\title{
A COMPARISON OF CALCULATED AND ESTIMATED OSMOLARITIES OF URINE
}

\author{
BY \\ M. H. ROSCOE \\ From the Department of Medicine, the University of Manchester
}

(RECEIVED FOR PUbLiCATION MAY 14, 1960)

\begin{abstract}
Osmolarity has been calculated from estimated cations and organic solutes in 200 samples of urine and compared with that found by direct osmcmetry.

In three-fifths of the samples the calculated value differs from the found by less than $5 \%$, but in some differences of over $30 \mathrm{~m}$.osmoles/l. and percentage differences of over 20 are found.

Calculated values are frequently too high, this overestimation being particularly marked in alkaline urines, and a change in reaction of the urine in one subject can alter the relationship of the calculated to the true osmolarity in the course of a few hours.

The findings in a small series of samples where the principal anions are estimated suggest that the osmolar activities of the solutes are less in the more alkaline urines than in the more acid ones.
\end{abstract}

When direct osmometry is not available calculations from the estimated solutes are frequently employed, but are subject to two sources of error acting in opposite directions, underestimation of solutes, giving low values, and overcalculation of osmolar activity, giving high values.

In this paper the found and calculated osmolarities of 200 samples of urine are compared.

\section{Methods}

The urine samples were from 20 experiments with 14 subjects. Each experiment gave at least eight samples with wide variation in minute volume and osmolar concentration, these being obtained by variations in fluid intake, or by giving pitressin or chlorothiazide. The scatter of osmolarity in each experiment prevents results at any osmolarity from being weighted by a preponderance of samples from single experiments.

The osmolarity was found from freezing point determinations made with a Fiske osmometer. The following methods of analysis were used: For $\mathrm{Na}$ and $\mathrm{K}$, flame photometry; for $\mathrm{NH}_{4}$ and urea, Conway (1933); for phosphate, Fiske and Subbarow (1925); for creatinine, Jaffe reaction; for Cl, Sanderson (1952), protein, turbidometric; for $p \mathrm{H}$, glass electrode.

In the major part of the work the osmolarities were calculated from $\mathrm{Na}, \mathrm{K}, \mathrm{NH}_{4}$, urea, creatinine, and protein if present. It was assumed that the three cations are present as chlorides and that their osmotic activity was similar to that of $0.2 \mathrm{M}$ solutions of these salts. Then the osmotic activity is the concentration in m.moles $\times 0.925$ $\times 2$ for $\mathrm{NaCl}$ and $0.93 \times 2$ for $\mathrm{KCl}$ and $\mathrm{NH}_{4} \mathrm{Cl}$. Urea and creatinine are assumed to behave as ideal molecules and their osmotic activity to be equal to their molar con- centrations. The ionizable and so osmotically active groups are calculated from Van Slyke's formula of g./1. $\times 0.243$. The Van Slyke factor is for solutions at

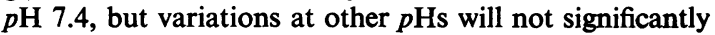
affect the total osmolarity since that due to protein is never greater than $10 \mathrm{~m} .0 \mathrm{sm}$./1. The urines in which anions and cations are calculated separately do not contain protein. In a few experiments phosphate and $\mathrm{Cl}$ were estimated and the contribution of each ion to the osmotic pressure of the solution was calculated separately, the osmotic coefficient suggested by Yardley (1958) being used. These are as follows:

\begin{tabular}{ll|ll}
$\mathrm{Na}^{+}$ & 0.95 & $\mathrm{Cl}^{\prime}$ & 0.92 \\
$\mathrm{~K}^{+}$ & 0.92 & $\mathrm{HPO}_{4}{ }^{\prime \prime}$ & 0.38 \\
$\mathrm{NH}_{4}{ }^{+}$ & 0.92 & $\mathrm{H}_{2} \mathrm{PO}_{4}{ }^{\prime}$ & 0.95 \\
\multicolumn{4}{|c}{} \\
\multicolumn{3}{|c}{ Results }
\end{tabular}

The mean differences between calculated and found osmolarities, with the variations given by the standard deviations, are shown in Fig. 1, the samples being grouped according to the found osmolarity.

When calculated values are greater than found (differences positive) the osmolar activity has been overestimated, but, since it is known that the analysis of solutes is incomplete, the overestimation of activity is in fact greater than that shown. When calculated values are less than found (differences negative) there is obvious underestimation of active solutes.

The mean values show increasing overestimation of activity with increasing osmolarity till this reaches $600 \mathrm{~m} .0$ smoles $/ 1$. At higher osmolarities this decreases and underestimation is apparent. 


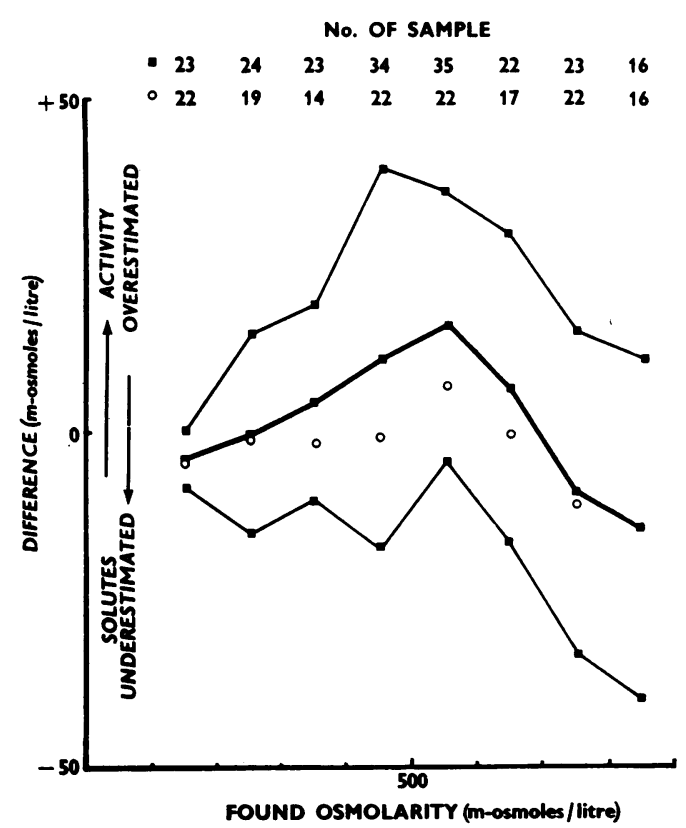

FIG. 1.-The differences between calculated and found osmolarity of urine. The calculated value is based on twice the sum of the concentrations of $\mathrm{Na}^{+}, \mathrm{K}^{+}$, and $\mathrm{NH}_{4}^{+}$, and the concentrations of urea, creatinine, and protein. $\square$ Mean values \pm standard deviation in 200 samples. O Mean values of samples when chlorothiazide had not been given.

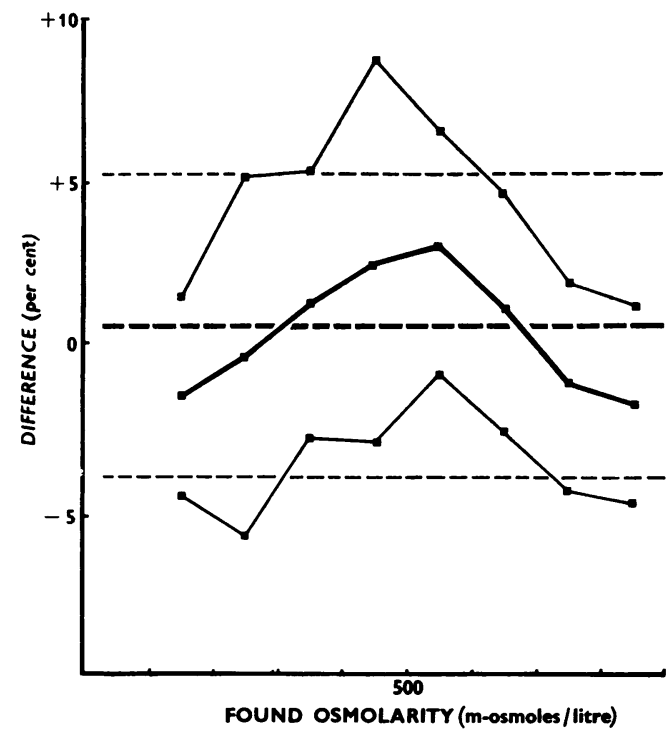

FIG. 2.-The percentage differences between calculated and found osmolarity in 200 samples of urine. Mean values and standard deviation at different osmolarities.
The percentage variations of the calculated from the found values are not large (Fig. 2). In the whole series the mean difference is small $(+0.75 \%)$ and $81 \%$ of the samples fall within a $5 \%$ difference. Underestimation in the samples of lowest and highest osmolarity is of similar percentage value. Overestimation is still maximal at 500 to $600 \mathrm{~m}$.osmoles/., in some cases being more than $20 \%$.

A high proportion of samples with overestimation were noticed to be from subjects who had had the diuretic chlorothiazide, and when these are removed from the series overestimation is only apparent in the mean figure for the one group with osmolarity of 500 to 600 m.osmoles/1. This is shown in Fig. 1 . The urine after chlorothiazide tends to be alkaline, so the effect of urinary hydrogen ion concentration was studied in five subjects where variations occurred spontaneously or were induced by giving chlorothiazide or ammonium chloride. The results in the form of linear regression lines, relating the differences to $p \mathrm{H}$, are shown in Fig. 3 . In three subjects there is a marked increase in overestimation of osmolarity as the $p \mathrm{H}$ rises, in two no significant change. The increase is not related to alteration of the found osmolarity, both high and low values occurring at all $p \mathrm{Hs}$. While these lines show the mean change with $p \mathrm{H}$, it is not suggested that the relationship is in fact linear, and since the molar concentrations and volumes of the samples vary considerably, no quantitative relationship is apparent.

In Fig. 4 the differences in one subject in 12 consecutive half-hour specimens are shown (open circles). They vary from +31 m.osmoles 1 . at $p \mathrm{H}$

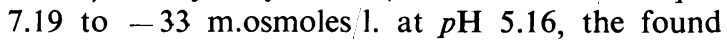

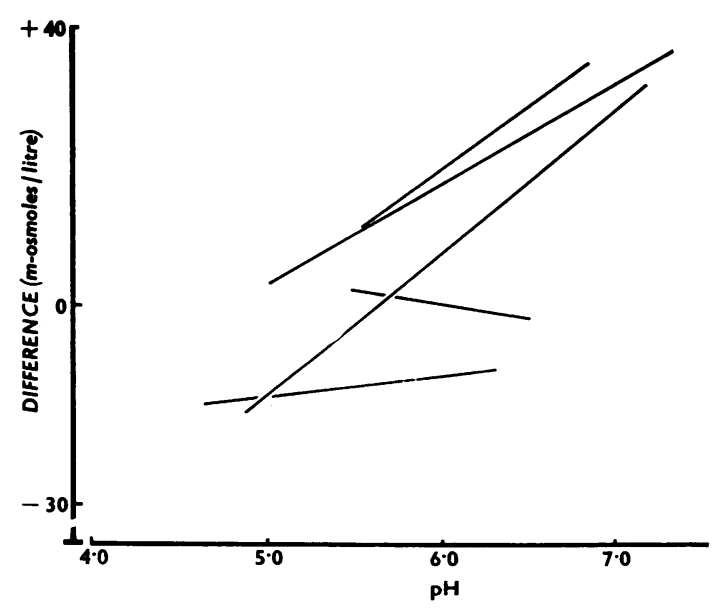

FIG. 3.-The effect of $p \mathbf{H}$ on the differences between calculated and found osmolarity in urines from five subjects, eight to twelve samples in each. The lines are linear regression equations. 


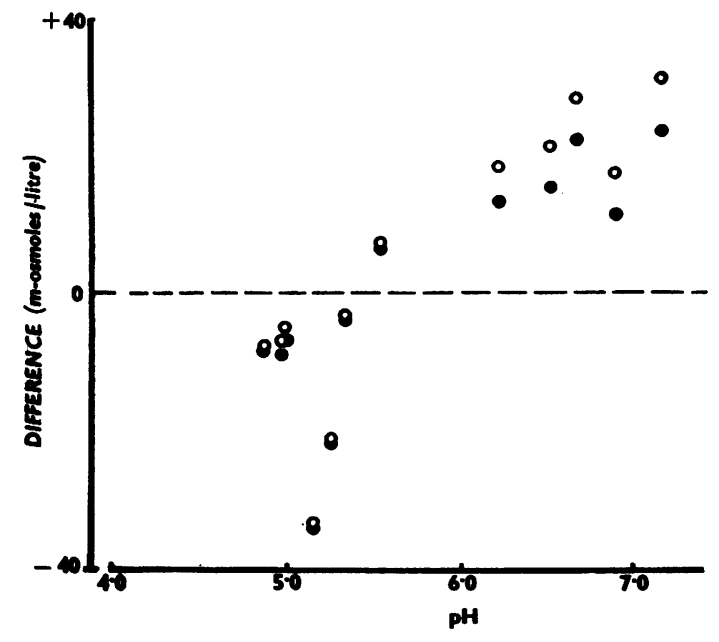

Fig. 4. -The effect of $p H$ on the differences between calculated and found osmolarity in successive samples from one subject. O Total difference. Difference corrected for phosphate activity.

osmolarities in these two samples being 737 and 895 m.osmoles 1 . respectively. Thus the true difference between the two samples, $158 \mathrm{~m}$.osmoles/1., appears from the calculated figures to be only $94 \mathrm{~m} .0$ smoles $/ 1$.

The two most obvious possibilities to account for this change are that the osmotic activity of phosphate is reduced in alkaline urine owing to the increase in the proportion of $\mathrm{HPO}_{4}{ }^{\prime \prime}$ to $\mathrm{H}_{2} \mathrm{PO}_{4}$, and that there is less chloride, the anion with a high osmolar activity. These anions were estimated in the three experiments in which overestimation of osmolarity rose with increasing alkalinity. Some of the overestimation is eliminated if the change in phosphate activity is allowed for. This is shown for one experiment in Fig. 4 where the closed circles show the figures corrected by subtraction of the difference between molar concentration of phosphate and its estimated osmotic activity. The mean reduction in overestimation in this experiment is $26 \%$, in the other two with clear overestimation it is 11 and $16 \%$ respectively. No part of the change can be attributed to alterations in the $\mathrm{Cl}$ concentration, as the ratio $\mathrm{Cl}^{\prime} /$ cations does not change with $\mathrm{pH}$.

If, when chloride and phosphate are estimated, the osmolarity is calculated from these anions, the estimated cations and organic solutes, instead of assuming that the anion is chloride in amounts equivalent to the cations, the calculated values are less in all cases than the found, because the anion estimation is grossly incomplete. These osmolar differences are shown in Fig. 5 for the three experiments referred to in the last paragraph, and may be compared with those in Fig. 1. The calculated

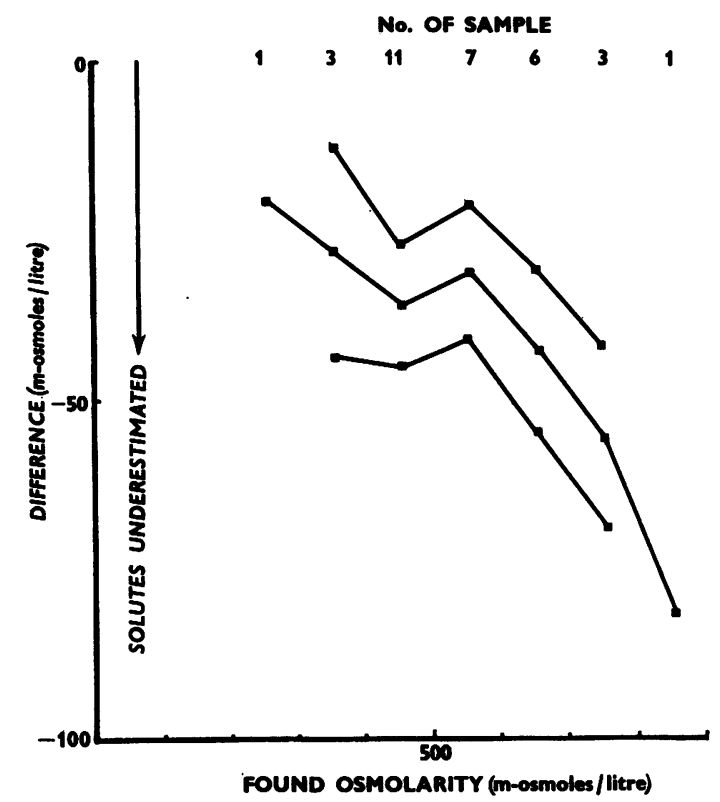

FIG. 5.-The difference between calculated and found osmolarity of urine. The calculated value is based on the concentrations of $\mathrm{Na}^{+}, \mathrm{K}^{+}, \mathrm{NH}_{4}^{+}, \mathrm{Cl}^{\prime}, \mathrm{HPO}_{4}^{\prime}, \mathrm{H}_{2} \mathrm{PO}_{4}^{\prime}$, urea, creatinine, and protein. Mean values \pm standard deviation in 32 samples.

TABLE I

ANION AND OSMOLAR GAPS IN URINES OF DIFFERENT HYDROGEN ION CONCENTRATION

\begin{tabular}{|c|c|c|c|c|c|c|c|c|c|c|c|}
\hline \multirow{4}{*}{ Subject } & \multirow{4}{*}{$\begin{array}{c}\text { No. of } \\
\text { Samples }\end{array}$} & \multirow{4}{*}{$p H$ Range } & Cations & Anions & \multirow{2}{*}{\multicolumn{2}{|c|}{ Anion Gap }} & \multirow{2}{*}{\multicolumn{3}{|c|}{$\begin{array}{c}\text { Osmolarity } \\
\text { (m.osmoles/1.) }\end{array}$}} & \multirow{2}{*}{\multicolumn{2}{|c|}{$\frac{\text { Osmolar Gap }}{\text { Anion Gap }}$}} \\
\hline & & & \multicolumn{2}{|c|}{ (m.Eq./1.) } & & & & & & & \\
\hline & & & \multirow{2}{*}{ Mean } & \multirow{2}{*}{ Mean } & \multirow{2}{*}{ Range } & \multirow{2}{*}{ Mean } & \multirow{2}{*}{$\begin{array}{l}\text { Found } \\
\text { Mean }\end{array}$} & \multicolumn{2}{|c|}{ Found-Calculated } & \multirow{2}{*}{ Range } & \multirow{2}{*}{ Mean } \\
\hline & & & & & & & & Range & Mean & & \\
\hline 1 & $\begin{array}{l}6 \\
6\end{array}$ & $\begin{array}{l}4 \cdot 86-5 \cdot 00 \\
5 \cdot 55-7 \cdot 19\end{array}$ & $\begin{array}{l}161 \\
214\end{array}$ & $\begin{array}{l}122 \\
159\end{array}$ & $\begin{array}{r}17-53 \\
22-94\end{array}$ & $\begin{array}{l}39 \\
55\end{array}$ & $\begin{array}{l}619 \\
569\end{array}$ & $\begin{array}{l}20-81 \\
12-70\end{array}$ & $\begin{array}{l}49 \\
35\end{array}$ & $\begin{array}{l}1.02-1.53 \\
0.55-0.75\end{array}$ & $\begin{array}{l}1.25 \\
0.61\end{array}$ \\
\hline 2 & $\begin{array}{l}6 \\
6\end{array}$ & $\begin{array}{l}5 \cdot 00-5 \cdot 20 \\
6 \cdot 64-7 \cdot 34\end{array}$ & $\begin{array}{l}167 \\
234\end{array}$ & $\begin{array}{l}128 \\
174\end{array}$ & $\begin{array}{l}27-60 \\
46-77\end{array}$ & $\begin{array}{l}40 \\
60\end{array}$ & $\begin{array}{l}524 \\
561\end{array}$ & $\begin{array}{l}24-54 \\
16-48\end{array}$ & $\begin{array}{l}33 \\
31\end{array}$ & $\begin{array}{l}0.52-1.15 \\
0.33-0.76\end{array}$ & $\begin{array}{l}0.86 \\
0.49\end{array}$ \\
\hline 3 & $\begin{array}{l}3 \\
5\end{array}$ & $\begin{array}{l}5.48-5.67 \\
6.06-6.86\end{array}$ & $\begin{array}{l}70 \\
89\end{array}$ & $\begin{array}{l}21 \\
20\end{array}$ & $\begin{array}{l}45-58 \\
58-79\end{array}$ & $\begin{array}{l}50 \\
69\end{array}$ & $\begin{array}{l}398 \\
437\end{array}$ & $\begin{array}{l}27-46 \\
31-45\end{array}$ & $\begin{array}{r}39 \\
39\end{array}$ & $\begin{array}{l}0.60-0.98 \\
0.55-0.73\end{array}$ & $\begin{array}{l}0.80 \\
0.57\end{array}$ \\
\hline
\end{tabular}


values fall below the found by a mean of $7 \%$, no consistent variation occurring with osmolarity. The differences are also shown in Table I, grouped according to the $p \mathrm{H}$, together with the anion gap, or difference between estimated cations and anions, which is a measure of unestimated anions. Then the ratio osmolar gap : anion gap also given is an indication of the osmolarity of the unestimated anions, and it is seen that this is reduced in the more alkaline urines, or the osmolar activity of the unestimated anions decreases as the $p \mathrm{H}$ rises. It is thus not surprising that the calculated values exceeded the found in the more alkaline urines, when the anion was assumed to be chloride, with its high osmotic activity. The ratios are not an exact measure of the activity because cation estimation is also incomplete and the anion gap larger than that shown; they are therefore all too high. This explains the fact that the activity is in some cases apparently greater than 1.0.

\section{Discussion}

The osmolarities, calculated from the concentrations of the major cations and organic solutes, vary from the true values by less than $5 \%$ in a high proportion of the samples, and this at first sight suggests that such values can be used as reliable measurements, for variations of this order are often due to experimental error. But the fact remains that in some cases the differences are greater than $5 \%$ and that, since one factor producing wide variations has been found, the differences, at least in some cases, are true ones.

This factor is the hydrogen ion concentration of the urine. As the $p \mathrm{H}$ rises there is an increasing tendency for the calculated osmolarities to be too high, suggesting that the activity of the unestimated anions has decreased. Such a decrease is known to occur in the case of phosphate and this accounts for part of the overestimation in the experiments where phosphate is estimated, but not all.

The anion gap has been calculated in the experiments where the $p \mathrm{H}$ is known, from the difference between $\mathrm{Na}^{+}, \mathrm{K}+$ and $\mathrm{NH}_{4}{ }^{+}$concentrations and $\mathrm{Cl}^{\prime}$ and phosphate concentrations, and compared with the osmolar gap, or difference between the found osmolar activity and the sum of the theoretical activities of all the estimated solutes. In the more alkaline urines the osmolar gap is smaller compared with the anion gap than in the more acid urines.
This suggests two possibilities: that as the urine becomes more alkaline an increasing proportion of the unestimated anion is a substance of low osmotic activity, or that the activity of known or unknown solutes decreases with increasing alkalinity, possibly as a result of the formation of non-dissociating complexes. One substance of low activity which is known to increase in the urine, with alkalosis, is the trivalent ion, citrate (Evans, MacIntyre, Macpherson, and Milne, 1957), but the maximal increases in excretion recorded by these authors are less than $8 \mu \mathrm{Eq}$./min., amounts which can only account for part of the difference between more acid and more alkaline urines found here.

The results are all given as concentrations, and calculations of the minute excretions have not been made because it is felt that, when the calculated concentrations are incorrect, multiplication by the minute volume merely adds to the complexity. The percentage differences between found and calculated osmolarities are, however, the same for excretion rates as for concentrations. In the whole series, based on anion as chloride, the mean difference between solute excretion and osmolar excretion is not significant (Fig. 2), but in the $41 \%$ of samples where there is overt underestimation of solute excretion this is $3 \%$, measured by its osmolar activity. In the series where some anions are estimated the mean underestimation is $7 \%$.

The most recent study of urine osmolarity is that of Yardley (1958), who made full analyses of 24-hour specimens of normal and pathological urine. The calculated osmolarities were always less than the found values by a mean of $10.6 \%$, but anion analysis was here also shown not to be complete. This figure may be compared with the present one of $7 \%$ in the small series with separate anion analysis.

Thus it has been shown that calculation of the osmolarity from known concentrations of solutes can only give figures of uncertain value, but it should be pointed out that the reverse process of finding the solute content from the known osmolarity is even more unreliable, since the activities of the different solutes are so variable and the hydrogen ion concentration has so great an effect.

\section{REFERENCES}

Conway, E. J. (1933). Biochem. J., 27, 430.

Evans, B. M., MacIntyre, I., Macpherson, C. R., and Milne, M. D. (1957). Clin. Sci., 16, 53.

Fiske, C. H., and Subbarow, Y. (1925). J. biol. Chem., 66, 375.

Sanderson, P. H. (1952). Biochem. J., 52, 502.

Yardley, H. J. (1958). Clin. Chim. Acta, 3, 280. 